\title{
CAMINHOS E DESAFIOS NO PROCESSO DE FORMAÇÃO DO PROGRAMA DE PÓS-GRADUAÇÃO EM DESENVOLVIMENTO REGIONAL SUSTENTÁ VEL (PRODER): UMA ANÁLISE DAS FALAS DOS EGRESSOS
}

\author{
Verônica Salgueiro do Nascimento* \\ Lúcia Rabello de Castro*** \\ Domingos Arthur Feitosa Petrola* \\ José Ferreira Lima Júnior*
}

\begin{abstract}
RESUMO
A criacão da Universidade Federal do Cariri, na cidade de Juazeiro do Norte, Ceará, propiciou uma mudanca no cenário universitário do interior do estado. Inicialmente ligada à Universidade Federal do Ceará, o campus atendia à acão de expansão do sistema federal de educação superior. Foram criados cursos de graduação e um Programa de Pós-graduacão em Desenvolvimento Regional Sustentável (PRODER). Diante da necessidade de debrucar-se criticamente sobre as experiências do programa, tornou-se relevante investigar os significados construídos pelos educandos através da formação no mestrado, refletindo a transformacão subietiva dos envolvidos. A pesquisa é decorrente de estágio pós-doutoral, sendo construída a partir de dois instrumentos de coleta de dados: grupo focal, e um questionário online. Percebeu-se que o mestrado contribuiu para a fixacão do jovem na sua região de origem, e que as falas foram complementares, sendo possível relacionar o aspecto da construcão compartilhada do conhecimento com a forma de "ver além" que o mestrado proporciona através da interdisciplinaridade.
\end{abstract}

Palavras-chave: Ensino superior. Mestrado. Pós-graduação.

\section{INTRODUÇÃO}

O presente texto apresenta uma parte dos resultados da pesquisa realizada no decorrer do estágio Pós-doutoral realizado pela autora principal sobre supervisão da segunda autora. Contamos com a colaboração dos outros dois autores na composição do instrumento de pesquisa e na fase de análise dos dados. O objetivo deste trabalho foi investigar sobre o significado da formação no mestrado e refletir sobre o processo de subjetivação dos estudantes envolvidos na pesquisa.

Inicialmente, gostaríamos de demarcar alguns pressupostos teóricos que nos orientaram no decorrer da realização da pesquisa. O primeiro deles diz respeito ao entendimento de uma posição ativa dos pesquisados. Ressaltamos a importância da

\footnotetext{
*Psicóloga. Doutora em Educação (UFC). Professora da Universidade Federal do Cariri (UFCA). Coordenadora do Programa de Pós-Graduação em Desenvolvimento Regional Sustentável (PRODERUFCA).

**Psicóloga. Doutora em Psicologia (Universidade de Londres). Professora do Instituto de Psicologia e do Programa de Pós-Graduação em Psicologia (UFRJ).

***Psicólogo. Mestre em Desenvolvimento Regional Sustentável (UFCA). Professor do curso de Psicologia da Faculdade Maurício de Nassau e da Faculdade Luciano Feijão.

****Cirurgião-dentista. Doutor em Biotecnologia (UFPB). Bolsista CAPES de Pós-doutorado vinculado ao PRODER/UFCA. Professor da Escola Técnica de Saúde de Cajazeiras, da Universidade Federal de Campina Grande.
} 
participação do sujeito pesquisado na tessitura da pesquisa. Com este exercício dialógico nos foi possível potencializar a voz do pesquisado (sujeitos da pesquisa egressos).

Outro elemento orientado de nossa ação refere-se ao cunho dialógico da pesquisa. Trabalhamos com a compreensão de que a fala é um "elemento que delineia o traçado da história dos homens, mulheres e crianças, e que, portanto, pode destiná-los a convivências mais democráticas ou mais autoritárias" (CASTRO, 2010, p. 21). O compartir reflexões em grupo a respeito de experiências reforça o registro democrático em seus processos educativos.

Por último, assinalamos ainda que nos alinhamos com o referencial da pesquisa intervenção. Esta perspectiva teórica reforça que "O 'campo de pesquisa' se constitui a partir e com a presença do pesquisador" (CASTRO, 2008, p.37). A participação do pesquisador e sua interação com o grupo pesquisado é fator determinante para a construção das interpretações para as falas compartilhadas.

\section{CONTEXTO DA PESQUISA}

O Mestrado Acadêmico do Programa de Pós-Graduação em Desenvolvimento Regional Sustentável (PRODER), ligado anteriormente à Universidade Federal do Ceará (UFC) - Campus Cariri, e agora à Universidade Federal do Cariri (UFCA), foi autorizado pela Coordenadoria de Aperfeiçoamento de Pessoal de Nível Superior (CAPES) em novembro de 2010, e deu início à sua primeira turma em fevereiro de 2011. Na última avaliação da CAPES, foram analisadas suas atividades nos dois primeiros anos de funcionamento, e o mestrado manteve a nota 3 (três). Em todas as turmas foram selecionados 20 alunos, exceção feita à segunda, que selecionou 15 discentes.

O objetivo principal do Programa é promover a formação de mestres, proporcionando uma abordagem interdisciplinar do desenvolvimento à luz dos novos paradigmas e da modernidade ética. $\mathrm{O}$ fato de se localizar territorialmente em um espaço historicamente excluído dos processos de desenvolvimento, o interior do estado do Ceará, em pleno Sertão Semiárido, imprime ao Programa uma responsabilidade redobrada. O PRODER nasce com o compromisso de interferir positivamente na formação social e econômica da região que o abriga. Ele foi o primeiro curso de mestrado ofertado pela instituição.

O curso está estruturado em torno de uma Área de Concentração, Desenvolvimento Regional Sustentável, tendo seus estudos capilarizados em duas linhas de pesquisa: Ambiente e Desenvolvimento Regional Sustentável; e Sociedade, Estado e Desenvolvimento Regional Sustentável. 
A instalação da UFCA neste território traz em si um imenso desafio: a formação diferenciada de novos profissionais, sobretudo no que diz respeito aos espaços da produção do conhecimento para além da sala de aula, enfatizando a prática da pesquisa, da cultura e da extensão comprometidas com a transformação local. A possibilidade de reverter o fluxo migratório para os grandes centros urbanos constitui-se numa oportunidade relevante de contribuir para a permanência dos jovens em sua região para que possam, num futuro próximo, converter o seu processo de formação individual em benefício coletivo para suas comunidades de origem. Chacon (2008) ressalta o aspecto do deslocamento de importantes recursos financeiros e humanos para a região gerando repercussões na esfera do poder público, na iniciativa privada e em toda a sociedade. Gianella (2011), ao se reportar aos desafios que essa experiência nos coloca, chama a atenção para um possível conflito entre o aspecto de inovação ou ruptura e o aspecto da repetição ou reafirmação de uma velha maneira de entender o mundo.

Enfatizamos que o PRODER tem como principal desafio contribuir com a produção de conhecimentos para fortalecer o processo de desenvolvimento, com foco especial para o Sertão Semiárido do Nordeste brasileiro. De forma ampla esta proposta traz implícita a necessidade de uma abordagem interdisciplinar para fomentar e consolidar pesquisas sobre temas relativos aos processos de desenvolvimento de uma região. O tema exige uma análise que perceba sua complexidade, e isto só pode ser alcançado a partir da abordagem baseada nas dimensões da sustentabilidade (social, ambiental, econômica e institucional). O pressuposto inicial é que uma região é resultante de um processo de construção social e político, marcado por limites e potencialidades que a particularizam.

Queremos salientar a necessidade da prática constante de reflexões a respeito dos impactos gerados pela presença dessa Universidade na região em foco. Nessa direção nos propomos a contribuir com a discussão ao investigar a experiência de formação de jovens pesquisadores oferecida pelo PRODER.

\section{DO PERCURSO METODOLÓGICO}

A metodologia adotada alinha-se com o referencial da pesquisa qualitativa. Esta se mostra como a mais adequada aos propósitos do presente trabalho. As metodologias qualitativas derivam da convicção de que a ação social é fundamental na configuração da sociedade (HAGUETE, 2000). A abordagem qualitativa responde a questões particulares e preocupa-se com um nível de realidade que não pode ser quantificado. Ela trabalha com o universo de significados, motivações, crenças e valores, o que corresponde a uma dimensão relacional mais profunda, não apropriada a quantificações.

Inicialmente desenvolvemos dois encontros com o grupo focal e posteriormente 
fizemos também o registro de informações a partir de um questionário. O procedimento adotado foi construir uma ferramenta em um sítio da internet, e disponibilizar o endereço para acesso através do e-mail dos egressos. As respostas à pesquisa foram coletadas de forma organizada e automática em um sistema de planilhas totalmente online, onde foram catalogadas segundo a data de realização.

O questionário foi composto por duas partes. A primeira delas objetivou registrar informações sobre o sexo, a idade, o local onde reside e a formação inicial dos participantes. A segunda parte trouxe perguntas abordando temas como: atividade profissional que desenvolvia antes do mestrado e onde trabalha após essa formação pósgraduada; tempo de permanência no curso; formas utilizadas para publicação de textos científicos antes e depois do mestrado; dificuldades sentidas durante esse percurso e depois desta experiência; dimensões da sustentabilidade relacionadas ao trabalho de dissertação e o significado da vivência do mestrado para cada um.

Privilegiaremos neste texto a análise das respostas a esse instrumento que foi enviado em outubro de 2014 para todo o grupo de egressos da primeira turma (20 pessoas), dos quais trezes responderam.

Por último, demarcamos que a análise das falas será feita de acordo a técnica da triangulação dos dados (SOUZA; ZIONI, 2003), tecida a partir das falas dos pesquisados, do referencial dos autores em foco e das análises dos pesquisadores.

\section{RESULTADOS E DISCUSSÕES}

Inicialmente apresentamos os dados da distribuição percentual segundo o sexo dos participantes da pesquisa. Conforme descrito no gráfico abaixo, verificamos que houve um número maior de respostas de pessoas do sexo feminino. 
Gráfico 01. Distribuição percentual dos participantes segundo sexo.

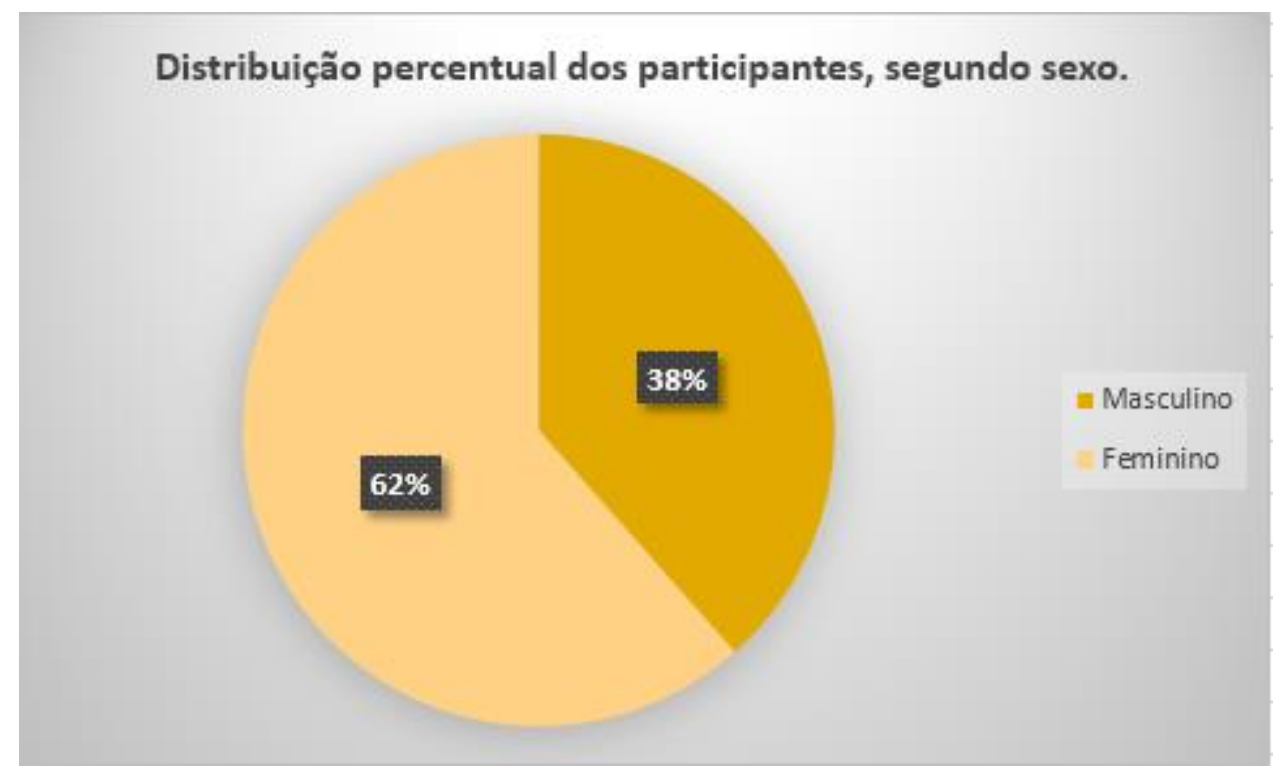

Fonte: Elaboração dos Autores, 2014.

Em seguida, apresentamos os resultados referentes ao tempo de permanência do discente no programa, o que se configura como o período desde a entrada até a data da defesa da dissertação.

Gráfico 02. Distribuição percentual do tempo de permanência discente no PRODER

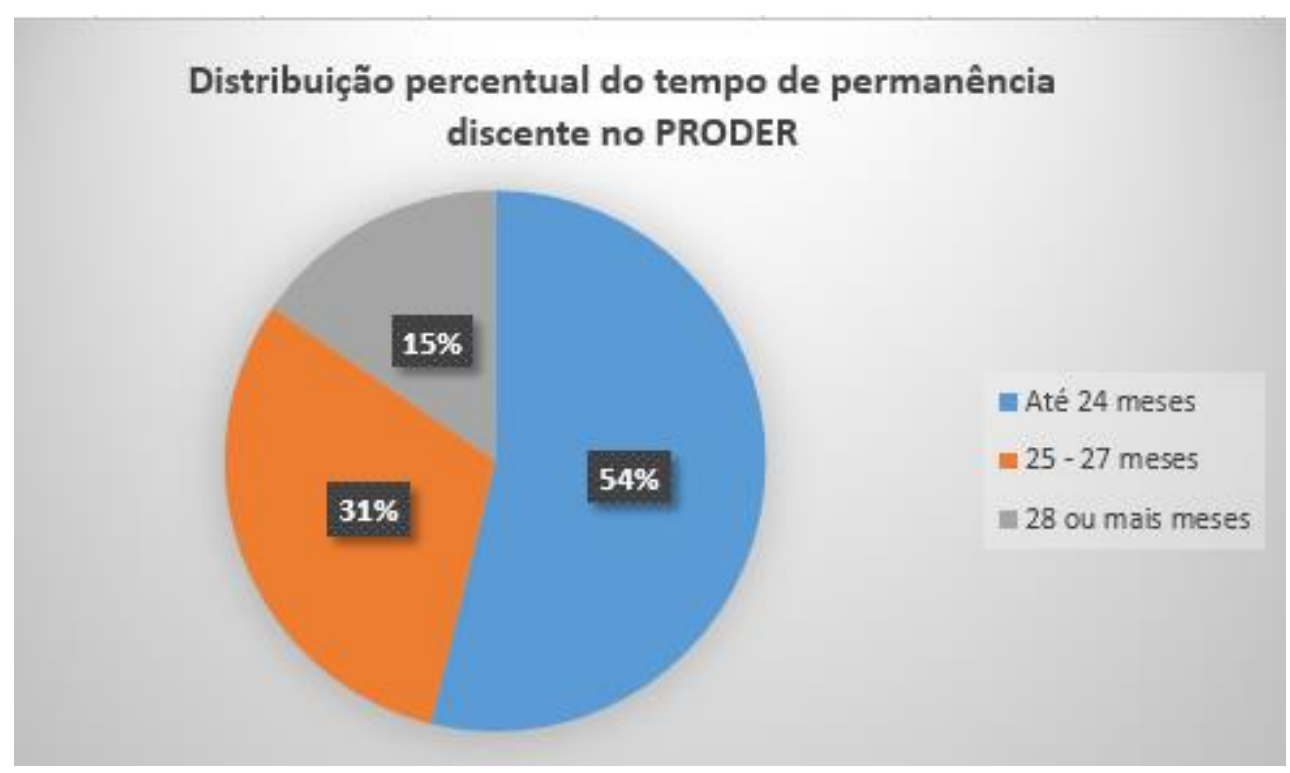

Fonte: Elaboração dos Autores, 2014.

No que diz respeito a correlação entre as dimensões da sustentabilidade e a dissertação, ainda que entendendo as dimensões como complementares e indispensáveis 
umas às outras, quando as estratificamos, a percepção dos egressos elenca prioritariamente a Dimensão Social como sendo aquela mais utilizada no processo de escrita e reflexão no mestrado, sendo seguida pelas dimensões Ambiental, PolíticoInstitucional e, por último, a Econômica, conforme percebe-se no gráfico 03.

Gráfico 03. Correlações entre as dissertações defendidas e as Dimensões da Sustentabilidade

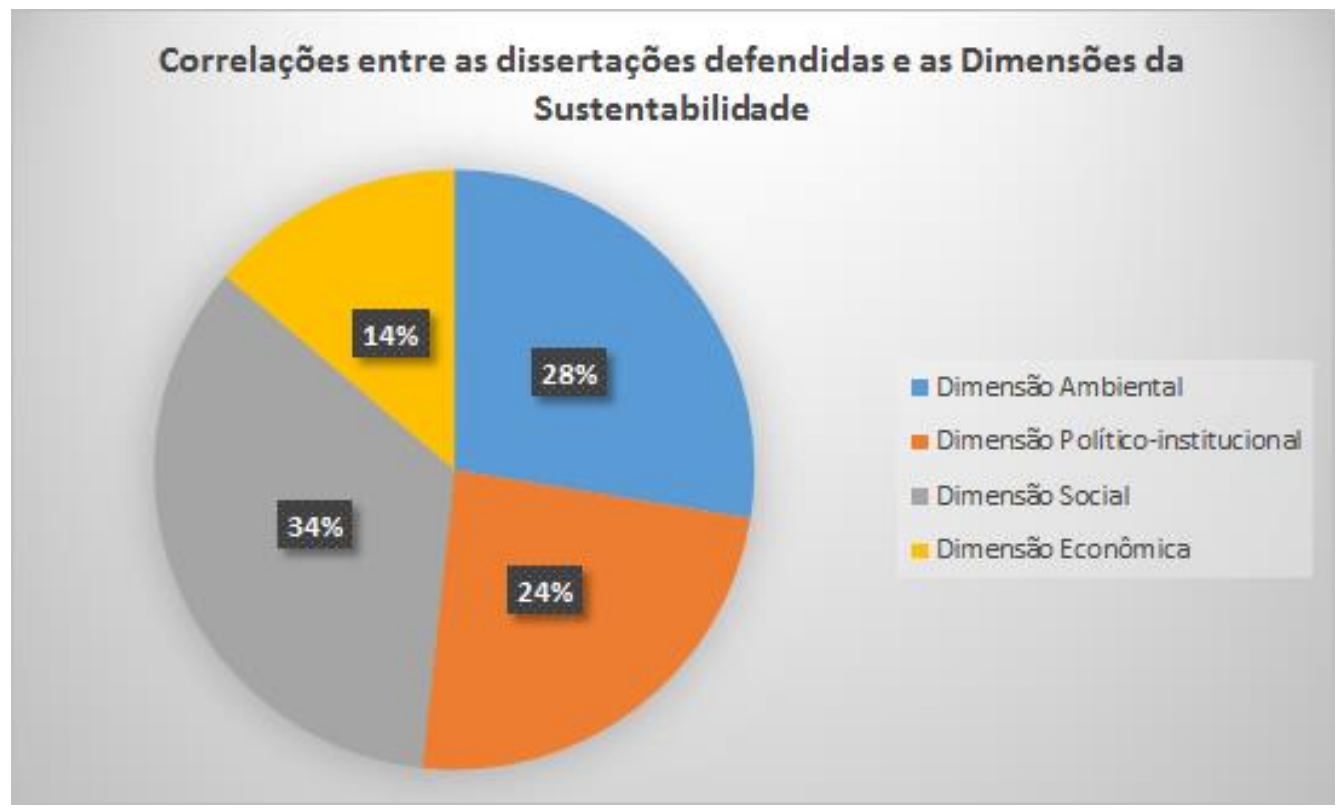

Fonte: Elaboração dos Autores, 2014.

A idade dos participantes da pesquisa localiza-se entre 26 e 54 anos. Sendo que a maior parte encontra-se por volta de 30 anos, caracterizando assim um grupo relativamente jovem.

O grupo também apresentou diferentes formações no nível de graduação, situando-o com um forte aspecto interdisciplinar.

Todos moravam no Cariri cearense e permaneceram na região após a defesa, com exceção de dois egressos que estão fazendo doutorado em Recife. A permanência da maior parte do grupo na mesma região nos leva a entender que o mestrado contribuiu para a fixação do jovem no seu local de origem favorecendo o rompimento com uma antiga prática migratória para outras áreas consideradas como "mais desenvolvidas".

Como principal dificuldade encontrada no decorrer da formação do mestrado, o grupo apresenta a difícil definição de seu objeto de pesquisa e o exercício próprio que envolve o desenvolvimento da pesquisa. Isso pode se justificar pela pouca prática de pesquisa na formação anterior desses sujeitos. Podemos relacionar este fato também ao baixo índice de publicação de artigos em periódicos científicos após a defesa da dissertação.

Posteriormente, o grupo indicou que a principal dificuldade destacada foi a 
reinserção no mercado de trabalho, sendo que em grande parte, os egressos estão desenvolvendo atividades com relação à docência.

Apresentaremos nesta parte do texto algumas respostas dos participantes da pesquisa relativas ao significado da experiência do mestrado:

Pessoalmente me fez crescer como ser humano, enxergar o mundo com outros olhos respeitando as diferenças, dificuldades e particularidades de cada um.

Contribuições diversas como possibilidades de crescimento profissional, de investimento na docência e o passaporte para ingresso no doutorado. Além da incorporação dos preceitos da sustentabilidade, sobretudo, o pensar no próximo, a minha vida pessoal.

Aprofundar os estudos em sustentabilidade. $O$ contato com a interdisciplinaridade fez com que aprendesse a ter um olhar holístico sobre as diferentes questões. Aprender a produzir com profissionais de diferentes áreas.

Como anteriormente descrito, o programa de mestrado é interdisciplinar, são várias as modalidades de graduação. Podemos indicar que esta marca da interdisciplinaridade trouxe um diferencial para a formação dos participantes.

O novo a ser construído passa por um processo de graduação que também se aproxime de questões interdisciplinares. Um processo de formação que se comprometa com a construção do tipo de conhecimento-emancipação, "buscando superar a ignorância representada pelo colonialismo" (OLIVEIRA, 2008, p.21).

De acordo com o que levantamos sobre o que se discute em torno do termo interdisciplinaridade, podemos concluir que o conceito ocupa o centro das atenções, está na 'moda', mas não é novidade (MAHEU, 2010). Ou seja, há muito tempo se discute o conceito, mas não se consegue alcançar a consolidação de práticas interdisciplinares.

No cenário das pesquisas sobre esse termo, Fazenda (2009, p. 13) apresenta algumas reflexões pertinentes ao nosso estudo, a autora indica que "O primeiro passo para a aquisição conceitual interdisciplinar seria o abandono das posições acadêmicas prepotentes, unidirecionais e não rigorosas que fatalmente são restritivas, primitivas e 'tacanhas' impeditivas de aberturas"; buscar o estranhamento do que se estabeleceu como padrão; problematização do que é posto na busca do pensar de forma ambígua; "Exercitar uma forma interdisciplinar de teorizar e praticar educação demanda, antes de mais nada, o exercício de uma atitude ambígua" (FAZENDA, 2009, p. 13). 
Como desfecho desta parte do texto, destacamos que a análise do conteúdo das falas nos permite estabelecer conexões com as ideias de Freire (2007, p. 119) quando afirma que uma das tarefas da formação acadêmica a ser desenvolvida seria $o$ compromisso com a curiosidade epistemológica, sem deixar de lado a imaginação criadora que busca desvelar a verdade, ressaltando "Refiro-me à tarefa, não importa qual seja a atividade universitária - a da docência, a da pesquisa ou da extensão - de desocultar verdades e sublinhar bonitezas".

\section{DESAFIOS PARA O PROGRAMA}

O desafio inicial trazido pelas falas dos participantes é o desconhecimento por parte da maioria da população a respeito do foco principal do mestrado, ou seja, o tema do Desenvolvimento Regional Sustentável. Para o entendimento amplo desta questão, convém demarcar toda a complexidade presente no pensar e no fazer Desenvolvimento Sustentável. A princípio, restringiu-se sua compreensão aos aspectos ecológicos e econômicos, no entanto, o termo tem evoluído (CAMARGO, 2003) de forma a envolver aspectos que contemplam a relação de interdependência entre meio ambiente e desenvolvimento humano. Nessa direção, Sachs (2007, p. 22) afirma: "trabalho atualmente com a ideia de desenvolvimento socialmente includente, ambientalmente sustentável e economicamente sustentado. Ou seja, um tripé formado por três dimensões básicas da sociedade".

Para muitos autores, o termo mais recentemente cunhado e que daria conta de um movimento mais complexo seria Sustentabilidade. Em consonância com este posicionamento, acrescentamos a afirmação de Gadotti (2006, p.114) "Sustentabilidade não tem a ver apenas com a Biologia, a Economia e a Ecologia. Sustentabilidade tem a ver com a relação que mantemos conosco mesmos, com os outros e com a natureza". De acordo com este posicionamento, acrescentamos que abordar a temática do desenvolvimento sustentável e da sustentabilidade significa discutir sobre o papel do ser humano, da natureza e de suas conexões, "sobre a vida que circula no planeta terra, casa comum da humanidade" (CALOU; CHACON; NASCIMENTO; SAMPAIO;, 2013, p.3).

No cenário atual, é inegável que, o debate sobre este termo vem assumindo o centro das atenções. $\mathrm{O}$ interesse pelo entendimento deste conceito tem crescido e estabelece palco propício para o diálogo entre vários segmentos da sociedade em geral. No entanto, estamos longe de alcançar "um consenso quanto ao seu real significado, quanto a como implementá-lo e mesmo quanto à possibilidade de sua implementação em âmbito global" (CAMARGO, 2003, p. 15).

Desta forma, o nosso grande desafio como desdobramento de nossa investigação 
é percebermos o quão urgente e necessário se faz envidar esforços que possam contribuir para a problematização do termo Desenvolvimento Sustentável. Sobretudo, a partir da pesquisa realizada, pensamos em contribuir com o debate e com a sistematização de novos conhecimentos das realidades locais e cotidianas. Convidamos os egressos do mestrado para pensar conosco sobre tal temática e agora o leitor deste artigo para que juntos possamos tornar nosso "o desafio de pensar, expor e ouvir o outro sobre a questão da sustentabilidade" (SORRENTINO, 2011, p.19), reforçando a percepção de que tais reflexões são ancoradas em nossa inserção no tecido social no qual nos encontramos todos envolvidos.

Lembrando que sustentabilidade significa participação democrática e redução de desigualdades sociais, e diminuição de pobreza monetária, devendo, portanto, reestruturar as forças produtivas e mudar um sistema que gera situações-limite quase que intransponíveis, por meio de uma racionalidade ecológica, que nos faça conscientes de todos os danos que estão atualmente colocando o planeta em risco face ao modelo de vida-consumo-devastação que criamos e ao qual estamos submetidos (NASCIMENTO; PETROLA, 2014).

Outro desafio consiste na consolidação do caráter interdisciplinar presente na formação oferecida pelo PRODER. Ao refletir sobre as falas dos pesquisados e o referencial dos autores apresentados, nos indagamos: quais são as possíveis estratégias que o PRODER deve implementar para consolidar práticas pautadas na leitura de mundo e no desvelamento crítico das realidades; intervenções solidárias (saber social e para o outro) e que nos aproximem de um saber-fazer interdisciplinar?

Um dos caminhos que poderiam nos aproximar de práticas profissionais interdisciplinares seria que a formação dos mestrandos pudesse proporcionar o aprofundamento deste referencial. Práticas de pesquisa, de cultura, de extensão e docência que possam ser solo fértil para o florescimento e desenvolvimento do pensarfazer interdisciplinar.

Mas como alcançar isto no cenário atual e da formação inicial (graduação)? Percebemos como preocupante a profissionalização docente pertinente ao contexto contemporâneo que deveria passar por uma formação interdisciplinar, ou seja, "Formar educadores que entendam melhor seus alunos e a si mesmos, que entendam melhor o que é um ser humano da maneira mais contextualizada possível” (MAHEU, 2010, p.168).

Severino $(2009$, p. 37) defende que o modelo de educação a ser abraçado deve proporcionar e fortalecer processos de mediações existenciais. Ensino só se legitima se for mediador da educação, e se "Garantir que a educação seja mediação da percepção das relações situacionais, que ela lhes possibilite a apreensão das intrincadas redes políticas da realidade social”. 
Como último elemento, o desafio maior refere-se a um tema que traduzimos em alguns questionamentos: Como consolidar uma cultura permanente de publicação? E como fazer isso sem cair num simples ativismo mecânico de publicar em quantidade? A preocupação consiste em assegurar um sentido maior e includente para esta produção. $\mathrm{O}$ presente estudo não tem o caráter conclusivo e nem o compromisso de produzir uma única resposta a tais questionamentos, principalmente queremos contribuir com o aprofundamento de tais pontos de reflexão.

Para finalizar essa parte do texto, assinalamos que no contexto de formação de novos pesquisadores em uma nova universidade entendemos ser necessária a ousadia de fazer diferente e construir o novo possível.

\section{CONSIDERAÇÕES FINAIS}

Figueiredo (2009, p.57) aborda a importância da problematização dos conceitos estudados enfatizando que no processo educativo "precisamos estabelecer uma rotina de problematizar, de perguntar, de se espantar, de admirar”. Nessa direção, o autor nos convida a refletirmos sobre o movimento contínuo de elaboração do conhecimento e a nos comprometermos com o lugar ativo de construtores dos saberes. Tal posicionamento encontra-se ancorado na proposta elaborada por Freire (2005) condensada na expressão Educação Libertadora.

No clima de respeito vivenciado durante toda a realização dos trabalhos cada integrante foi convidado a dizer "sua palavra" (FREIRE, 2001) sobre o significado do grupo. A partir dos resultados dessa experiência, entendemos que a expressão da fala dos sujeitos, no espaço educacional, pode cada vez mais ser incentivada. Para tanto, os educadores devem estar sensibilizados sobre a importância da prática que reforça o exercício da fala e da escuta. Ao refletir sobre esse ponto, Figueiredo (2009, p.57) indica um caminho a ser trilhado pelos educadores e educandos: o exemplo do docente que questiona e dialoga gentilmente com seus educandos "desse modo não há perguntas bobas nem respostas definitivas (...) nem desrespeito ao movimento de exercitar a curiosidade".

A relação dialógica apresenta-se como um caminho necessário a ser estabelecido. Para se efetivar este caminho, de acordo com Freire (2005), o diálogo deve estar pautado na humildade, no amor, na fé intensa no ser humano e na leitura crítica da realidade. Esse autor afirma que o diálogo é uma necessidade existencial. Ressalta que para existir o diálogo é preciso humildade, esse não pode significar um ato de arrogância. Como posso dialogar com alguém quando pré-julgo que esse nada tem a me oferecer? Na relação dialógica está inerente a dimensão da troca, para que isso aconteça é necessário ter a consciência da incompletude do ser humano. Sendo assim, homens e 
mulheres humildemente podem reconhecer suas limitações.

Gostaríamos de encerrar esse trabalho apresentando nossa concordância com as palavras da pesquisadora Lúcia Rabello de Castro a respeito das dimensões da participação que entendemos como fundamental para o presente trabalho de investigação "Participar deslancha sempre um processo de busca, pertencimento e ação criadora" (CASTRO, 2010).

No contexto do grupo pesquisado, um dado a ser ressaltado, refere-se ao fato de que todos os egressos são oriundos da própria Cariri cearense. A maior parte fez sua graduação fora da região. Estes demonstram grande entusiasmo por terem o meio de se capacitarem em seu local de origem. Ressaltamos a oportunidade que esses sujeitos tiveram de permanecer em seus sítios. De acordo com Zaoual (2008, p. 86), sítio é entendido como espaço simbólico de pertencimento, entendido ante de tudo como uma pátria imaginária, ou seja, entidade imaterial. É também compreendido como patrimônio coletivo que estabelece sua concretude no espaço de convivência entre os atores.

Ao final de nossas reflexões, gostaríamos de sublinhar que, a partir da análise das respostas dos participantes da pesquisa, percebemos que as falas dos sujeitos se complementam e podemos relacionar o aspecto da construção compartilhada do conhecimento com a forma de ver além que o mestrado proporcionou. Que o peso das cobranças advindas do paradigma reprodutivista que alimenta a competitividade não apequene a alma desses novos pesquisadores. Que possam romper com a roda viva que nos absorve num ritmo alienador. "Tão habituados nos encontramos à ordem formal convencionalmente estabelecida, que nos incomodamos ao sermos desafiados a pensar com base na desordem ou em novas ordens que direcionem ordenações provisórias e novas" (FAZENDA, 2009, p.13).

Por último, gostaríamos de enfatizar o sentido utópico assumido no horizonte de nossas reflexões. "Mas se é verdade que a paciência dos conceitos é grande, a paciência da utopia é infinita" (SANTOS, 2010, p. 346). Entendemos que as reflexões suscitadas a partir das falas dos sujeitos de pesquisa alinham-se com o desejo de superação do paradigma dominante, buscando contribuir com o movimento de afirmação de um outro paradigma emergente em que o pensar e o fazer a sustentabilidade se inscreve. Trata-se então da construção de uma utopia coletiva que nos sentimos construindo nas nossas práticas cotidianas sociais e pedagógicas (REIGOTA, 2012). Não é tarefa fácil, nem é uma tarefa individual.

\section{REFERÊNCIAS}

CALOU, R.; NASCIMENTO, V.; K.; CHACON, S. Desenvolvimento Sustentável e Cultura de Paz: conceitos passíveis de um processo de ensino e aprendizagem. Revista 
Terceiro Incluído, v.3, n.2, p. 1-10, 2013.

CAMARGO, A.L.B. Desenvolvimento Sustentável: dimensões e desafios. $6^{\mathrm{a}}$ ed. São Paulo: Papirus, 2003.

CASTRO, L.R. Conhecer, transformar (-se) e aprender: pesquisando com crianças e jovens. In: CASTRO, L.R.; BESSET, V.L. (Orgs). Pesquisa e Intervenção na infância e juventude. Rio de Janeiro: FAPERJ; NAU editora. p.21-42, 2008.

CASTRO, L. R. Falatório: participação e democracia na escola. Rio de Janeiro: Contra-capa/FAPERJ, 2010.

CHACON, S. S. Construção de indicadores de sustentabilidade para a Avaliação do Desenvolvimento Regional do Cariri Cearense. Projeto de Produtividade em Pesquisa, CNPq, 2008.

FAZENDA, I. A aquisição de uma formação interdisciplinar de professores. In: FAZENDA, I. (Org). Didática e Interdisciplinaridade. 14ª ed. São Paulo: Papirus, 2009.

FIGUEIREDO, J.B.A. A questão é o problema. In: FIGUEIREDO, J.B.A; SILVA, M.E.H. Formação Humana e dialogicidade em Paulo Freire II. Fortaleza: Edições UFC, 2009.

FREIRE, P. Pedagogia do Oprimido. 42a ed. São Paulo: Paz e Terra, 2005.

2001.

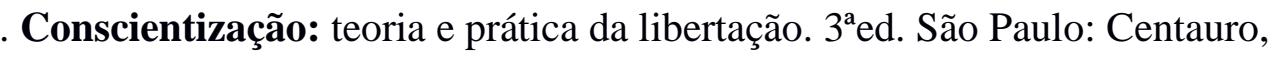
Educação e Política. São Paulo: Villa das Letras, 2007.

GADOTTI, M. Paulo Freire e a boniteza do sonho de ensinar-e-aprender com sentido. In: SCOCUGLIA, A. Paulo Freire na História da Educação do Tempo Presente. Porto: Edições Afrontamento, 2006.

GIANELLA, V. É para lá que eu vou: O processo de Interiorização da Universidade Federal no Brasil e o desafio do diálogo entre visões de mundo. In: CONGRESSO LUSO AFRO BRASILEIRO DE CIÊNCIAS SOCIAIS, 2011, Salvador. Anais... Salvador: UFBA, 2011.

HAGUETTE, T. Metodologias qualitativas na sociologia. Petrópolis: Vozes, 2000.

MAHEU, E. Interdisciplinaridade na formação inicial de professores. In: VEIGA, I.P.; ÁVILA, C. (Orgs). Profissão docente: novos sentidos, novas perspectivas. $2^{\mathrm{a}}$ ed. São Paulo: Papirus, 2010.

NASCIMENTO, V.S.; PETROLA, D.A.F. Educar para a paz e para a sustentabilidade: construindo caminhos para outro mundo possível. NAU Social, v.5, n.8, p. 71-82, 2014.

OLIVEIRA, I.B. Boaventura e a Educação. Ramada, Portugal: Edições Pedago, 2008. 
REIGOTA, M. Revendo utopias e espaço tempos que a educação ambiental nos possibilitou. In: MATHEUS, C.E.; MORAES, A,J. (Orgs). Educação Ambiental: momentos de reflexão. São Carlos: RiMa Editora, 2012.

SANTOS, B.S. Pela Mão de Alice: o social e o político na pós-modernidade. $13^{\mathrm{a} e d .}$ São Paulo: Cortez, 2010.

SACHS, I. Primeiras intervenções. In: NASCIMENTO, E.P.; VIANA, J.N. Dilemas e desafios do desenvolvimento sustentável no Brasil. Rio de Janeiro: Garamond, 2007.

SERRANO, G. Educação em valores: como educar para a democracia. $2^{a}$ ed. Porto Alegre, 2002.

SEVERINO, A.J. O conhecimento pedagógico e a interdisciplinaridade: o saber como intencionalização da prática. In: FAZENDA, I. (Org). Didática e

Interdisciplinaridade. $14^{\mathrm{a}}$ ed. São Paulo: Papirus, 2009.

SORRENTINO, M. Desenvolvimento sustentável e participação: algumas reflexões em voz alta. In: LOUREIRO, F.B. et al. Educação Ambiental: repensando o espaço da cidadania. 5a ed. São Paulo: Cortez, 2011.

SOUZA, F.; ZIONI, F. Novas perspectivas de análise em investigação sobre meio ambiente: a teoria das representações sociais e a técnica da triangulação de dados. Saúde e Sociedade. v.12, n.2. p.76-85, 2003.

ZAOUAL, H. Globalização e diversidade cultural. São Paulo: Cortez, 2008. 